\title{
É POSSÍVEL RELACIONAR AVALIAÇÃO DISCENTE E FORMACÃO DE PROFESSORES? A EXPERIÊNCIA DE SÃO PAULO
}

RESUMO: No contexto da política educacional paulista, busca-se relacionar os resultados do Sistema de Avaliação do Rendimento Escolar do Estado de São Paulo (Saresp) ao direcionamento de ações de formação de professores. Este trabalho amplia a análise teórica do texto original, produzido durante o mestrado da autora, que focou a articulação entre o Saresp e os programas de formação contínua da rede estadual. Partindo dos anúncios da relação presente nos documentos oficiais, questiona-se em que medida é pertinente elaborar programas e ações de formação e bonificação de professores, tendo como pressuposto que os resultados dos alunos nas avaliações ilustram as necessidades de formação dos docentes e o trabalho realizado pelos professores. Conclui-se que essa relação não é direta, apesar de ser defendida no âmbito de elaboração de políticas educacionais preocupadas com a gestão racionalizada do sistema educacional, e aponta-se a necessidade de estudos e debates mais aprofundados sobre o binômio formação de professores/resultados de desempenho de alunos.

Palavras-chave: Formação de Professores. Desempenho dos Alunos. Sistemas de Avaliação.

* Doutora em Educação pela Faculdade de Educação da Universidade de São Paulo (USP); Pesquisadora da Fundação Carlos Chagas (FCC) e Professora da Faculdade de Educação da Universidade de São Paulo (USP). E-mail: dri_bauer@yahoo.com.br 


\section{IS IT POSSIBLE TO RELATE STUDENT ASSESSMENTS TO THE TRAINING AND EDUCATION OF TEACHERS? THE SÃO PAULO EXPERIENCE}

ABSTRACT: Taking the context of São Paulo's educational policy, an attempt is made to relate teacher training programmes to the results of SARESP (São Paulo Evaluation System of Educational Performance). This work is an extension of a theoretical analysis carried out in the author's original text, produced for a Master's Thesis, focusing on the relationship between SARESP and educational, training programmes of the state. Going on statements made in official documents, concerning the current understanding of the relationship between the two, one wonders to what extent it is relevant to design programs, and teachers' training activities, using student performance during assessments, as indicative of what teachers require. The conclusion is reached that this relationship is not straightforward, despite being defended within educational policies concerned with the streamlined management of the educational system. Furthermore, the need for further discussion and studies on this coupling: teacher education/ performance of students results, is indicated.

Keywords: Further Educational Training of Teachers. Evaluation of Students. Students Performance and Results. Large Scale Assessment Systems.

\section{0 estudo: origens e contribuições para a discussão sobre os usos dos resultados das avaliações educacionais}

A avaliação de sistemas educacionais intensificou-se no início da década de 1990, tornando-se um ponto de destaque nas políticas públicas ligadas à educação, não só no Brasil, mas em diversos países.

Esse fenômeno, que muitos autores [AFONSO (1998), DIAS SOBRINHO (em FREITAS, 2002), FREITAS (2007)] relacionam à mudança do papel do Estado na educação, à necessidade de melhor gerenciamento dos recursos disponíveis e à necessidade de diagnóstico para a melhoria do ensino público, tem feito com que os sistemas de avaliação, muitas vezes calcados em provas de rendimento dos alunos, ocupem papel de destaque na agenda política educacional.

O Sistema de Avaliação do Rendimento Escolar de São Paulo (Saresp) foi formulado, segundo os documentos oficiais, em resposta à necessidade da Secretaria da Educação do Estado (SEE) de definir uma política clara de avaliação. Essa política estava inserida em um amplo movimento de reforma do ensino em São Paulo, que se iniciou na gestão do governador Mário Covas, em 1995, com Teresa Roserley Neubauer da Silva à frente da Secretaria da Educação. A introdução da avaliação de sis- 
tema foi parte de um repensar sobre a educação paulista, que inaugurou uma reforma administrativa e pedagógica nas diversas instituições responsáveis pelo ensino em São Paulo.

Tendo em vista que um dos objetivos do Saresp referia-se à indicação de novos caminhos para as políticas de formação, a autora propôs, em sua dissertação de mestrado, a análise das potencialidades e dos limites da utilização dos resultados da avaliação para a indicação de políticas de formação. A partir das colocações realizadas em documentos do programa de avaliação, foi possível estabelecer alguns questionamentos que permitiram investigar o problema proposto:

- Como o Saresp contemplava, na sua formulação, a questão da formação dos educadores? O que declarava era viável?

- Como profissionais da Secretaria da Educação do Estado de São Paulo, responsáveis pela formação, entendiam a relação entre a avaliação e a formação de professores?'

- Os resultados do Saresp estavam subsidiando a elaboração de programas de formação de professores? Como estava se estabelecendo a articulação entre essas duas iniciativas?

A magnitude política e pedagógica da rede estadual de São Paulo impôs alguns recortes para a viabilização do estudo qualitativo, de caráter exploratório, cujo foco recaiu sobre as propostas realizadas para os professores de Língua Portuguesa, do Ensino Fundamental, em especial das séries iniciais.

Até o momento de realização daquela pesquisa (2004-2006), as produções acadêmicas que analisavam o Saresp ou os programas de formação docente não focavam na relação específica em tela (avaliação versus formação docente), justificando um estudo empírico que se propusesse analisar se a relação vislumbrada estava se efetivando e contribuísse para o avanço do debate sobre os usos dos resultados do Saresp.

Naquele momento, buscou-se avaliar se ações de formação contínua de professores estavam sendo propostas a partir dos resultados da avaliação, delimitando o estudo a quatro Diretorias de Ensino da rede estadual paulista. A escolha das diretorias regionais de ensino como foco prioritário do trabalho deveu-se à sua posição na estrutura da Secretaria da Educação de São Paulo, que ocupa um nível intermediário entre os órgãos centrais e as escolas. 
Considerou-se, como hipótese, que os usos dos resultados das avaliações para a elaboração de estratégias e cursos de formação estariam atrelados à concepção de educação e qualidade da educação daqueles que eram responsáveis pela implementação das ações de formação nessas Diretorias, o que justificava o estudo sobre suas opiniões acerca da avaliação, de seus objetivos, e de seu entendimento sobre a relação entre avaliação de sistemas e qualidade da formação docente.

Neste artigo, não são apresentados resultados da pesquisa de campo, mas sim da análise documental realizada na construção do problema de pesquisa, ou seja, propõe-se uma análise das relações entre a formação dos professores e os resultados obtidos pelos alunos no teste padronizado paulista, visto que a existência dessa relação parece ter sido um pressuposto para a elaboração de dois programas importantes naquela política educacional: o Sistema de avaliação do Rendimento Escolar de São Paulo (Saresp) e o Programa de Educação Continuada (PEC).

A retomada dos resultados dessa pesquisa justifica-se na medida em que permite a discussão sobre os usos dos resultados do Saresp sob a ótica da formação de professores, contribuindo para a compreensão do que tem sido feito, por parte de órgãos gestores, como a Secretaria da Educação e as Diretorias de Ensino, para que essa formação seja aprimorada de acordo com a demanda do sistema educacional.

Além disso, acredita-se que a relevância do tema reside no fato de que, apesar de os documentos oficiais apontarem a relação entre os resultados do Saresp e o planejamento de políticas voltadas para os professores, inclusive já havendo iniciativas de atribuir bônus a professores a partir daqueles resultados, controvérsias na literatura mostram que não há consensos sobre a estreita relação entre o desempenho dos alunos em testes e a formação e o trabalho dos docentes, sendo importante instaurar o debate em torno dessa questão.

\section{0 Saresp contemplava a formação dos educadores?}

Em uma primeira análise, pode-se dizer que o Documento de Implantação do Saresp apresenta alguns argumentos para justificar a introdução da avaliação de sistemas na rede paulista. Um deles seria a participação da Secretaria Estadual de Educação (SEE) nas três primeiras 
aferições do Sistema de Avaliação da Educação Básica (Saeb)², momento em que teria ficado evidente o papel da avaliação como instrumento de gestão e melhoria da qualidade de ensino (SÃO PAULOb, 1996, p. 5).

Essa "melhoria da qualidade de ensino" aparecia atrelada à busca de mais "eficiência na prestação de serviços educacionais", que seria alcançada pela racionalização de recursos, pela descentralização da administração e das decisões pedagógicas e pela produção de informações sobre o sistema educacional (SÃO PAULOb, 1996, p. 5-6).

Um segundo argumento utilizado para justificar a implantação do Saresp era o imperativo de cada escola se reconhecer nos resultados da avaliação, caso que não ocorria com os resultados do Saeb, por seu caráter amostral.

Tendo em vista a intenção de implantar uma cultura avaliativa e fornecer informações sobre o desempenho dos alunos para as escolas, ter-se-ia optado por trabalhar com um sistema que abrangesse o universo da rede, inicialmente em algumas séries pré-fixadas e, posteriormente, de forma censitária. Dois objetivos gerais foram declarados para o Saresp:

- Desenvolver um sistema de avaliação de desempenho dos alunos dos ensinos Fundamental e Médio do Estado de São Paulo, que subsidie a Secretaria da Educação nas tomadas de decisão quanto à Política Educacional do Estado;

- Verificar o desempenho dos alunos nas séries do Ensino Fundamental e Médio, bem como nos diferentes componentes curriculares, de modo a fornecer ao sistema de ensino, às equipes técnico-pedagógicas das Delegacias de Ensino e às Unidades Escolares informações que subsidiem:

- a capacitação dos recursos humanos do magistério;

- a reorientação da proposta pedagógica desses níveis de ensino, de modo a aprimorá-la;

- a viabilização da articulação dos resultados da avaliação com $\mathrm{O}$ planejamento escolar, a capacitação e o estabelecimento de metas para o projeto de cada escola, em especial a correção do fluxo escolar (SÃO PAULOb, 1996, p. 7-8, grifos meus). ${ }^{3}$

No decorrer da história do Saresp, tais objetivos foram desmembrados em outros mais específicos que, contudo, não romperam com os objetivos iniciais, principalmente no que se refere à utilização dos resulta- 
dos para a reelaboração curricular e para a reorganização da trajetória escolar, bem como para a formulação de ações de "capacitação" de professores e técnicos da Secretaria da Educação.

Enfatizando a qualificação docente como fator preponderante da qualidade de ensino, e daí decorrendo a necessidade de formação contínua, a possível influência da avaliação de sistemas na formulação de políticas públicas de formação docente também foi explicitada por Bittar (1998), integrante da equipe de avaliação da Fundação para o Desenvolvimento da Educação (FDE), instituição responsável pelo gerenciamento das ações do Saresp.

Os resultados da avaliação, devidamente levados em conta, podem indicar caminhos para as atividades de capacitação propostas pelos órgãos centrais ou pelas DE para serem desenvolvidas junto às escolas ou, inversamente, para atividades por elas sugeridas às instâncias superiores [...]. As necessidades de capacitação são mapeadas a partir da análise dos dados do SARESP e outros indicadores de rendimento e procuram fortalecer o ensino justamente nos pontos do currículo em que o rendimento escolar se mostrou mais frágil. (BIT'TAR et al., 1998 , p. 5, grifos meus)

As diretrizes para a formação de professores aparecem mais explícitas no documento denominado Programa de Educaşão Continuada (1996-1998), no qual se retomavam as diretrizes para a política educacional definidas em 1995. Antecipando algumas das ações que seriam desenvolvidas, o documento assegura a pretensão de romper com os cursos de aperfeiçoamento desvinculados das reais necessidades dos participantes. O novo modelo pensado pela SEE previa articular teoria e prática, num movimento de ação-reflexão-ação, a partir do desenvolvimento de atividades interdependentes, que se alternavam contínua e sistematicamente (SÃO PAULOc, 1996).

As ações de educação continuada foram organizadas em dois níveis: o centralizado e o descentralizado. As ações do nível central teriam como prioridade as atividades voltadas para as lideranças educacionais, ou seja, para os Dirigentes de Ensino, os Supervisores de Ensino, os Assistentes Técnicos da Área Pedagógica das Oficinas Pedagógicas, os Diretores de Escola e os Professores Coordenadores. Essas atividades seriam desenvolvidas pelas universidades e outras instituições que atuassem na área de formação e aperfeiçoamento profissional. 
Já os professores seriam contemplados com ações planejadas e executadas pelas Diretorias de Ensino e suas Oficinas Pedagógicas, em parcerias com universidades e outras instituições atuantes na área de formação e aperfeiçoamento docente, tendo como objetivo suprir as necessidades formativas definidas no âmbito das diretorias.

Não eram mencionados, entretanto, em que tipo de dados a Diretoria de Ensino (D. E.) se apoiaria para fazer essa definição. Ao tratar da forma de diagnosticar os problemas enfrentados pela escola, observase uma rápida referência à avaliação como possível meio para obtenção de subsídios para definição do trabalho a ser realizado, sem mencionar diretamente o Saresp, talvez por este ainda não ser tão conhecido e comentado na rede, na época da formulação do documento.

Entretanto, Vera Lucia Wey, coordenadora da Cenp à época de implantação do programa, em material publicado posteriormente, destacava a importância das avaliações educacionais como balizadoras da demanda da SEE/SP pelos cursos (WEY, 1999, p. 230-231). Para ela, o Programa de Educação Continuada (PEC) foi um projeto inovador na medida em que buscou o "redirecionamento das ações de capacitação", explicando que, normalmente, a oferta de cursos não se preocupava com as demandas dos educadores. Segundo ela, o PEC rompia com essa lógica, ao partir da demanda dos educadores e dos órgãos intermediários (as delegacias de ensino), possibilitando que a capacitação apoiasse os professores na busca de soluções para os problemas encontrados, o que permitiria a potencialização dos resultados da ação formativa. Nesse sentido, Wey chamava atenção para o papel do Saresp no redirecionamento das práticas escolares:

O acompanhamento, a avaliação das ações e a utilização dos dados que expressam o desempenho de cada região e de cada escola vêm propiciando maior clareza do significado do percurso educacional dos alunos, e a descoberta, o fortalecimento e a ampliação de procedimento que levam a um trabalho de sucesso. Isso vem ocorrendo com a utilização dos indicadores organizados pela escola e dos dados do SARESP, para melhor direcionamento da prática da sala de aula e aprimoramento do trabalho da escola.

As próprias ações de capacitação, sejam elas com a escola como um todo ou dirigidas às diferentes áreas do conhecimento (Português, Matemática, Geografia, etc.), por apresentarem como características esse movimento de ir e vir, promovem o redirecionamento da formação permanente para o aprimoramento da equipe de profissionais responsáveis por atender a demanda e a expectativa da comunidade escolar (WEY, 1999, p. 232). 
Contudo, nos documentos analisados, não eram explicitados os motivos ou pressupostos teóricos que reforçavam a ideia de que haveria uma inter-relação entre os saberes dos alunos, expressados nos resultados do Saresp, e a formação dos professores, deixando a impressão de que tal relação, inquestionável, estava dada, ou seja, que havia uma relação entre a formação docente e os resultados obtidos nos testes.

Essa relação continuou sendo a tônica de políticas mais recentes, com foco maior na gestão dos recursos públicos. Em 2007, por exemplo, a Secretaria de Educação de São Paulo anunciou a formulação de um sistema de avaliação que visava a avaliar o trabalho de cada equipe escolar (diretor, professores, coordenadores e funcionários). A avaliação levaria em conta taxas aprovação/reprovação de estudantes de cada escola, os dados das avaliações (como Saresp, Saeb e Prova Brasil) e também indicadores conhecidos por afetar a qualidade da aprendizagem, tais como a presença de professores e a estabilidade da equipe escolar (SÃO PAULO, 2007).

Em 2008, a bonificação foi sistematizada na forma de Lei Complementar, na qual fica claro o pressuposto de que os resultados obtidos pela escola, "visando à melhoria e ao aprimoramento da qualidade do ensino público", devem ser valorizados por meio do pagamento de adicional pecuniário aos professores:

Artigo $1^{\circ}$ - Fica instituída, nos termos desta lei complementar, Bonificação por Resultados - BR, a ser paga aos servidores em efetivo exercício na Secretaria da Educação, decorrente do cumprimento de metas previamente estabelecidas, visando à melhoria e ao aprimoramento da qualidade do ensino público (SÃO PAULO, 2008).

Não há, contudo, consenso na literatura sobre as relações que parecem estar na base dessa política de bonificação, a saber, a relação entre atuação e formação docente e desempenho dos alunos em avaliações. Assim, o exame mais detalhado da posição de alguns autores, realizado na próxima seção, torna-se imprescindível para fomentar o debate. 


\section{Atuação e formação docente e desempenho dos alunos em avaliações: 0 debate}

Nos últimos 20 anos, têm proliferado estudos sobre a formação continuada ou em serviço dos professores como estratégia para desenvolvimento profissional, sua necessidade para a reforma educacional e seu papel na melhoria dos resultados escolares. Diversos autores apontam que essas ações de formação e desenvolvimento profissional têm sido colocadas no cerne das reformas educacionais (DESIMONE, 2009; GATTI, 2008; BORKO, 2004; AGUERRONDO, 2002; GARET; PORTER; GUSKEY, 2001; WILSON; BERNE, 1999; GUSKEY; SPARKS, 1991; 1996; 2002).

No Brasil, observa-se um impulso à educação continuada a partir da Lei de Diretrizes e Bases da Educação Nacional (Lei Federal n. 9.394/96), cujo Artigo $80^{\circ}$ estipula que o poder público deve estimular o desenvolvimento e a veiculação de programas de educação continuada. Além disso, a partir da instituição do Fundef e do Fundeb, verificou-se a operacionalização do marco legal presente na lei da educação nacional no que tange ao desenvolvimento profissional e à educação continuada (em serviço) dos professores pela vinculação de verbas públicas destinadas a sua concretização.

Gatti (2008) ressaltou que o tema da educação continuada adquiriu relevo no âmbito das políticas públicas em nível mundial na década de 1990, destacando documentos do Banco Mundial, do Programa de Promoção das Reformas Educativas na América Latina (Preal), da Unesco e do Fórum Mundial da Educação como importantes veiculadores da ideia de preparar melhor os professores.

De todo modo, a tendência a direcionar políticas públicas para a formação de professores aparece relacionada à possibilidade de melhoria da qualidade ${ }^{4}$ de ensino. Inclusive, trabalhos como os de Franco (2005) e Fuller e Clarke 5 (1994, apud BRUNNER, 2003) exploram a formação do professor como definidora da qualidade do ensino oferecido. Como mostra Prada (2001):

As políticas de qualificação da educação e os programas, projetos, campanhas que as concretizam, estão orientadas, ao menos intencionalmente, ao atendimento da "qualificação" dos professores, a qual para a maioria de políticos espertos, e pessoas em geral, é considerada o nó gordão da qualidade da educação. Esta 
“qualificação" é entendida mais no sentido da "eficácia e eficiência do trabalhador da educação" do que do ponto de vista do desenvolvimento do ser humano profissional e docente inserido na cultura local (escola), da região e do país onde trabalha. (PRADA, 2001, p. 98-99, grifos meus)

Esse discurso da formação docente como propulsora da qualidade de ensino, que encontra ressonância e parece embasar a prática de alguns gestores da educação, tem crescido em importância nos debates sobre fatores que influenciam a qualidade escolar, normalmente traduzida para o público na forma de resultados dos alunos em avaliações padronizadas.

Contudo, é importante destacar a necessidade de refletir atentamente sobre os discursos que indicam quase exclusivamente as atividades de formação contínua e de valorização do magistério como solução para a melhoria da aprendizagem dos alunos, como se o problema da qualidade do ensino se resumisse à formação docente e ao desempenho docente.

Não se pretende negar o papel dos professores (e, consequentemente, de sua formação) para a melhoria da qualidade de ensino. Todavia, a compreensão de que o conhecimento dos alunos depende, principalmente, do conhecimento e do desempenho do professor ignora outros fatores que influenciam o processo de aprendizagem, tais como status socioeconômico do estudante, background do aluno, características das escolas, tamanho de turma, qualidade dos materiais didáticos utilizados, as próprias políticas educacionais implementadas, entre outros fatores (SOARES, 2008). É preocupante perceber que a questão da melhoria da qualidade de ensino aparece, pelo menos nos documentos dos programas, relacionada principalmente à formação docente, sendo pouco citados outros fatores que influenciam nessa qualidade.

Corroborando essa preocupação, Torres (1998) chama a atenção para a necessidade de analisar criticamente os discursos de formação e valorização docente que têm sido produzidos nos últimos anos e que embasam algumas políticas educacionais.

A autora traz uma contribuição preciosa ao alertar que é preciso refletir sobre o uso político que é feito de algumas relações que ainda não são consensuais entre a comunidade científica. Para ela, isso demonstra a existência de "problemas com a investigação científica e com seu uso", já que certas conclusões, realizadas a partir de estudos 
pontuais, podem ser erroneamente generalizadas, a depender da posição e da intenção política dos envolvidos no debate. Segundo ela, é "recorrente legitimar posições e até decisões de política educativa a partir de (uma seleção parcial e interessada de) resultados de investigação" (TORRES, 1998, p. 175).

Torres considera questionável a relação direta entre os conhecimentos dos alunos, concretizados nos resultados das avaliações, e o desempenho e formação docente, mostrando que essa relação tem sido objeto de controvérsia entre estudiosos. Nas palavras da autora:

Não existe uma relação mecânica entre conhecimento do professor e aprendizagem do aluno ou entre capacitação do professor e rendimento escolar. não se pode esperar que cada ano de estudos, cada curso ou oficina de capacitação resulte imediata e necessariamente em quantidades mensuráveis de aprendizagem (melhorada) por parte do alunado. Esta visão corresponde a uma percepção da educação e da aprendizagem escolar que equipara escola e fábrica e vê o ensino e a aprendizagem à luz do modelo fabril insumo-produto (inputs-outputs) (TORRES, 1998, p. 175, grifos do autor).

Em sua revisão das pesquisas sobre os programas de formação disponíveis, Hilda Borko (2004) concluiu que, a despeito dos vultosos gastos com formação continuada para professores, nas diversas instâncias administrativas, as ações resultam inadequadas, fragmentadas, intelectualmente superficiais e deixam de considerar o conhecimento já acumulado sobre como os professores aprendem (BORKO, 2004, p. 4).

Adicionalmente, Souza (2006) acredita que a formação de professores tem desconsiderado a escola e seus contextos sociais e institucionais, tomando os professores como elementos isolados, razão pela qual, potencialmente, essas atividades não incidem sobre a prática docente ou sobre a escola. Para a autora, é necessário tomar a escola como lócus privilegiado da ação dos professores e as atividades propostas não podem desconsiderar os saberes já construídos por eles, concluindo que, enquanto não se romperem antigas concepções de formação continuada, pouco os resultados das escolas avançarão em função dela. Apesar da postura mais crítica de Torres (1998) e Souza (2006), a maioria das reformas educativas tem partido da premissa de que a educação continuada em serviço é boa por definição, pouco se questionando se as atividades de formação realmente fazem diferença. 
Há ainda os que se dedicam à problemática da avaliação docente baseada nos resultados dos alunos, tendência que vem sendo enfatizada juntamente com o desenvolvimento dos sistemas de avaliação (GUSKEY; SPARKS, 1996; 2002). Conforme explicado por Gatti (2011), a utilização dos dados de rendimento dos alunos como evidência da atuação do professor tem se tornado comum nas propostas de avaliação dos professores. Apesar de apontar a existência de estudos críticos às avaliações de docentes realizadas nessas bases, a autora frisa que "é preciso ponderar as críticas e procurar delinear formas avaliativas que possam ser vistas como mais consistentes" (GATTI, 2011, p. 80)

Outros autores, como Darling-Hammond (1999) e Brunner (2003), apontam a existência de relação entre rendimento do aluno e formação do professor. Brunner, por exemplo, se apoia em estudo realizado por Fuller e Clarke para concluir que a qualidade da docência é um aspecto central para a melhoria dos resultados escolares dos alunos. Segundo o autor, a qualidade do ensino seria determinada:

[...] pelas práticas de ensino do docente na sala de aula, pelo desenvolvimento profissional docente (conhecimento da matéria que ensina e capacidade de ensinar a alunos de diversas origens sócio-familiares) e os insumos (tamanho do curso, formação inicial e experiência do professor) (BRUNNER, 2003, p. 77-78).

Ante as controvérsias, aqui apenas ilustradas pelo posicionamento de dois, entre outros autores que se dedicam a esses estudos, fica a dúvida sobre qual seria a exata correspondência entre formação e trabalho do professor e aprendizagem do estudante. As ações que foram definidas no Programa de Educação Continuada parecem supor que essa correlação existe e é alta. No entanto, elas ignoram que essas correlações não são comprovadas facilmente, como já explicava Scriven, desde a década de 1980:

Uma variável que é positivamente correlacionada à outra pode ser usada pra inferir a presença da outra, mas não pode em geral ser usada para explicá-la ou avaliá-la. $\mathrm{O}$ uso incorreto de um correlato (ou um fator, na análise fatorial) como se ele fosse uma explicação de, um substitutivo para, ou um critério de avaliação válido de, outra variável são exemplos do que é aqui chamado de falácia da sub-rogação estatística (SCRIVEN, 1987, p. 11) ${ }^{6}$. 
$\mathrm{O}$ argumento de Scriven aponta que mesmo que houvesse correlação estatística entre formação continuada, desempenho do professor e desempenho dos alunos, não seria possível afirmar que formação ou desempenho docentes são explicação para o desempenho dos alunos, visto que a correlação não serve para provar relações de causa.

Nesse sentido, ainda que houvesse acordo na literatura sobre que a formação e o desempenho do professor fazem diferença em termos do aumento da aprendizagem dos estudantes, o grau em que essa relação ocorre precisaria ser melhor investigado. Além disso, como salientado por Scriven, a utilização de testes psicológicos ou cognitivos pode ser válida ou inválida; então é importante analisar que tipo de informação pode ser obtida por meio da prova e discutir quão adequada é esta informação:

Procedimentos de avaliação, como usos de testes psicológicos, são válidos ou inválidos. Eles são válidos na extensão em que identificam corretamente o mérito do que ou de quem está sendo avaliado. (O tipo de validade envolvida em ambos os casos é a mesma, chamada validade de constructo, para a qual todos os outros tipos se reduzem) (SCRIVEN, 1987, p. 9) ${ }^{7}$.

Complementarmente, Haertel lembra outra importante questão com implicação para essa discussão: é possível reduzir as necessidades de formação dos professores a apenas alguns domínios de conhecimento dos alunos privilegiados no instrumento de avaliação?

(...) testes podem medir somente um subconjunto de importantes objetivos de aprendizagem, e se os professores são classificados de acordo com a aquisição dos seus alunos naqueles objetivos, o ensino em objetivos não-mensurados deveria ser desprezado (Elliott; Hall, 1985). Por todas essas razões, tem se tornado um lugar comum que conhecimentos dos alunos em testes estandartizados são inadequados para avaliação de professores (HAERTEL, 1986, p. 46). ${ }^{8}$

Ora, se as avaliações de rendimento dos alunos são pautadas em Matrizes de Conteúdos, que já constituem uma redução do currículo, seriam os resultados dos alunos nessas avaliações um bom espelho das necessidades formativas dos professores e de seu desempenho em sala de aula? Na mesma linha, em âmbito nacional, Gatti (2011) assinala a necessidade de refletir sobre as medidas provenientes do rendimento dos alunos, ao relacioná-las ao desempenho dos professores, destacando que são 
necessários "cuidados para que sejam assumidas como válida e confiável pelos avaliados" (GATTI, 2011, p. 80).

Deve-se considerar, ainda, que esses testes não levam em consideração as diferenças entre os alunos quando começaram a escolarização. Se programas de desenvolvimento profissional de professores baseiam-se nos resultados de avaliação em larga escala, seria necessário avaliar níveis anteriores de conhecimento dos alunos para poder isolar os efeitos do ensino e, assim, tentar compreender a influência da formação do professor sobre o conhecimento adquirido durante o ano letivo. No entanto, avaliações em larga escala raramente consideram habilidades preexistentes que os alunos trazem. Seria necessário realizar uma ampla discussão sobre como avaliar essas habilidades e o que deveria ser avaliado, a fim de determinar o efeito da escola e do professor sobre o aluno.

Uma última questão a ser considerada refere-se à gestão das diferenças de aprendizagem entre os alunos. Se a aprendizagem do estudante está diretamente relacionada à qualidade e à formação do professor, como seria possível explicar as diferenças entre os estudantes que tiveram o mesmo professor? E como essas diferenças seriam contabilizadas no momento de propor um curso de formação docente a partir dos resultados dos alunos? Qual é a necessidade de formação de um professor que é eficaz para alguns alunos, mas não para outros? Essas questões estão sendo levadas em conta por aqueles que propõem os cursos para os professores?

Em síntese, mesmo que se comprovasse a causalidade da relação entre a formação docente e o rendimento dos alunos, não seria possível deixar de apontar alguns problemas a serem considerados ao utilizar os resultados dos testes para a elaboração de programas educacionais: a natureza, a confiabilidade e a validade das informações produzidas pelo teste.

Não se pretende defender que os resultados dos testes não possam ser utilizados para a tomada de decisões, mas sim chamar a atenção para o fato de que esse uso não pode ser realizado de forma simplista, sem que a natureza da informação por eles produzida seja considerada. A validade das informações obtidas e dos instrumentos utilizados nas avaliações parece ter sido pouco questionada por aqueles que são responsáveis pela análise e pela elaboração das políticas, e por aqueles que recebem e interagem, em nível local, com esses resultados.

Nesse sentido, considera-se que a falta de debate e reflexão sobre a validade desses resultados, por si só, seria uma limitação para o 
seu uso que deveria ser considerada no momento da elaboração de ações a serem realizadas a partir deles. Tais questões não parecem estar sendo consideradas pelos gestores educacionais e por aqueles que elaboram as avaliações, já que a intenção de usar os resultados para o planejamento de ações de formação docente, ou mesmo para a oferta de informações educacionais para que o professor gerencie seu trabalho, tem sido apontada como objetivo em vários sistemas de avaliação do Brasil ${ }^{9}$, inclusive no Saresp.

Ante as controvérsias citadas e os problemas destacados, faz-se necessário o desenvolvimento de estudos empíricos que possam iluminar a relação entre formação e desempenho docente e rendimento dos alunos, ou seja, sobre como os resultados de rendimento podem auxiliar na orientação de atividades de formação contínua de professores e em que medida esses resultados refletem o desempenho do professor e se são boas medidas para serem usadas em políticas de bonificação. É necessário aprofundar a análise das relações entre rendimento dos alunos e formação e desempenho docente.

Esse aprofundamento parece ganhar em relevância ante a afirmação de Navarro (2003). Em material produzido para o Seminário Internacional "A dimensão política da avaliação da qualidade educativa na América Latina", o autor argumentou que as reformas educativas que ocorreram na maioria dos países latino-americanos a partir da década de 1980, no geral, não estão produzindo mudanças significativas no fazer do professor na sala de aula e nos resultados das avaliações. Tal constatação parece um contrassenso e merece atenção por parte daqueles que se debruçam sobre essa problemática.

Com o objetivo de compreender melhor as relações entre as avaliações de sistemas e os programas de formação docente a partir delas realizados, busca-se, em Wills (1992), citado por Franco (2005), informações que auxiliem no entendimento do problema. Segundo Franco, Wills é um pouco cético no que se refere ao uso dos resultados de rendimento escolar como subsídio para "soluções positivistas de políticas públicas", já que considera difícil identificar e medir muitos dos fatores que são associados aos processos escolares, devido à sua complexidade e ao seu caráter multifacetado.

Franco frisa que o "desempenho educacional dos alunos depende de diversos fatores, muitos dos quais estão além do controle dos pro- 
fessores" (FRANCO, 2005, p. 24). Da mesma forma, há que se supor que muito do desempenho do professor em sala de aula depende de outros fatores, além de sua formação ou do treinamento que ele recebe para atuar de acordo com os parâmetros curriculares e metodológicos determinados pelos gestores.

Em seu estudo, o autor faz uma reflexão sobre as possibilidades e os limites de vários tipos de avaliação para a obtenção de informações sobre a profissão docente. A partir de sua reflexão, exposta no Quadro 1, é possível inferir que seria importante procurar agregar às avaliações de desempenho do aluno outros instrumentos capazes de diagnosticar a influência do trabalho docente nos resultados obtidos, assim como detectar com mais precisão outros fatores que podem ser associados à melhoria desses resultados.

Além disso, parece importante desenvolver mecanismos de avaliação dos programas de formação oferecidos aos professores, a fim de verificar sua efetividade no desenvolvimento profissional docente.

QUADRO 1. Avaliações e Carreira do Magistério: potencialidades, limitações e alternativas

\begin{tabular}{|c|c|c|c|}
\hline AVALIACÃO (TIPO) & POTENCIALIDADES & LIMITACÕES & ALTERNATIVAS \\
\hline $\begin{array}{l}\text { Desempenho } \\
\text { de alunos }\end{array}$ & $\begin{array}{l}\text { Sintonizada com o propósito da } \\
\text { educação: aprendizagem dos } \\
\text { alunos. }\end{array}$ & $\begin{array}{l}\text { Muitos fatores estão fora do } \\
\text { controle das escolas e dos } \\
\text { professores. Mesmo no que } \\
\text { depende da escola, o desempen- } \\
\text { ho dos alunos é influenciado por } \\
\text { vários professores. }\end{array}$ & $\begin{array}{l}\text { Focalizar a melhoria da escola } \\
\text { ao longo do tempo, em vez do } \\
\text { desempenho em determinado } \\
\text { momento. Conjugar aspectos } \\
\text { coletivos, dependentes da } \\
\text { equipe da escola, com individuais, } \\
\text { dependentes de cada professor. }\end{array}$ \\
\hline Institucional & $\begin{array}{l}\text { Assume a escola como unidade } \\
\text { de análise. }\end{array}$ & $\begin{array}{l}\text { Risco de burocratização } \\
\text { Não produz informação sobre } \\
\text { cada docente. }\end{array}$ & $\begin{array}{l}\text { Articulá-la com indicadores } \\
\text { objetivos apurados por } \\
\text { avaliação externa. Conjugá-las } \\
\text { com outros critérios. }\end{array}$ \\
\hline $\begin{array}{l}\text { Conhecimentos e } \\
\text { competências } \\
\text { de professores }\end{array}$ & $\begin{array}{c}\text { Produz indicador para cada } \\
\text { docente. }\end{array}$ & $\begin{array}{l}\text { Conhecimentos e competências } \\
\text { podem não garantir boas práticas. }\end{array}$ & Articulá-la com outros critérios. \\
\hline $\begin{array}{l}\text { Desempenho de } \\
\text { professores }\end{array}$ & $\begin{array}{l}\text { Produz indicador para cada } \\
\text { docente. Similar à avaliação de } \\
\text { outros servidores, feita por } \\
\text { meio de preenchimento de } \\
\text { questionários e fichas. }\end{array}$ & $\begin{array}{c}\text { Risco de burocratização e } \\
\text { irrelevância. }\end{array}$ & $\begin{array}{l}\text { Articulá-la com indicadores } \\
\text { objetivos apurados por avali- } \\
\text { ação externa sobre a escola, } \\
\text { em especial com os fatores } \\
\text { que promovem bom } \\
\text { desempenho discente. }\end{array}$ \\
\hline
\end{tabular}

FONTE: FRANCO, 2005. 
Também seria fundamental compreender que efeitos as avaliações têm tido no trabalho realizado pelos professores e pelas escolas, assim como nas instituições que são responsáveis pela formação do professor. Conforme demonstrado por Bauer (2011), poucas são as pesquisas que se dedicam ao estudo dos efeitos das avaliações (a exemplo das de CARVALHO; MACEDO, 2010; PIATTI, 2006; BARREIROS, 2003), quer por sua complexidade metodológica, quer por dificuldades oriundas da própria alteração que ocorre nos programas, que inviabiliza o planejamento de pesquisas de longo prazo.

De qualquer forma, é necessário criar mecanismos para superar os limites e dificuldades impostos por avaliações de impacto, a fim de enfrentar o debate que apenas se inicia. A simples apreensão do uso dos resultados da avaliação nos órgãos intermediários e nas escolas para a reflexão sobre os fazeres e saberes da docência já poderia contribuir para iluminar a discussão, que, segundo Franco, deve se acirrar nos próximos anos, com a necessidade imposta pela Lei de Diretrizes e Bases da Educação Brasileira de se equacionar a avaliação da educação com a avaliação docente e a valorização do magistério. 


\section{Referências}

AFONSO, A. Políticas educativas e avaliação educacional. Portugal: Universidade de Minho, 1998.

AGUERRONDO, I. Los desafios de la política educativa relativos a las reformas de la formación docente. In: CONFERÊNCIA REGIONAL EL DESEMPEÑO DE LOS MAESTROS EM AMERICA LATINA Y EL CARIBE: Nuevas Prioridades. Anais... Brasília, DF: Unesco/MEC/BID, jul. 2002.

BARREIROS, D. R. A. O Sistema Nacional de Avaliação da Educação Básica: vínculos entre avaliação e currículo. Rio de Janeiro: Universidade Estadual do Rio de Janeiro, 2003.

BAUER, A. Avaliação de impacto de formação docente em serviço: o Programa Letra e Vida. Tese (Doutorado em Educação), 250p. São Paulo: Universidade de São Paulo/ Faculdade de Educação, 2011.

BITTAR, H. A. F. et al. O Sistema de Avaliação de Rendimento Escolar do Estado de São Paulo: Implantação e Continuidade. Idéias, São Paulo: FDE, n. 30, p. 9-20, 1998.

BORKO, H. Professional Development and Teacher Learning: Mapping the Terrain. Educational Researcher, v. 33, n. 8, 2004. Disponível em: <http://www.aera.net/ uploadedFiles/Journals_and_Publications/Journals/Educational_Researcher/Volume_ 33_No_8/02_ERv33n8_Borko.pdf>. Acesso em: 17 set. 2010.

BRUNNER, J. J. Limites de la lectura periodística de resultados educacionales. UNESCO. Evaluar las evaluaciones: una mirada política acerca de las evaluaciones de la calidad educativa. Buenos Aires: IIPE/UNESCO, 2003, p. 67-84.

CARVALHO, G. F. da S.; MACEDO, M. do S. A. N. Avaliação oficial: o que dizem os mediadores da política pública sobre o impacto na prática docente. Estudos em Avaliação Educacional, São Paulo: Fundação Carlos Chagas, v. 21, n. 46, p. 243-270, maio/ago. 2010. DARLING-HAMMOND, L. Teacher quality and student achievement. a review of state policy evidence. Seattle-WA: Center for the Study of Teaching and Policy; University of Washington, 1999.

DESIMONE, L. M. Improving impact studies of teacher's professional development: toward better conceptualizations and measures. Educational Researcher, Thousand Oaks, CA: Aera/Sage Publications, v. 38, n. 3, p. 181-199, 2009.

DIAS SOBRINHO, J. Campo e caminhos da avaliação: a avaliação da educação superior no Brasil. In: FREITAS, L. C. (Org.). Avaliação: construindo o campo e a crítica. Florianópolis: Insular, 2002.

FRANCO, C. Estudo sobre Avaliação da Educação e Valorização do Magistério. CONSED RH- GT Valorização do Magistério. Março de 2005. Disponível em: http:/ / www.consed.org.br/gcs/file.asp?id=6418. Acesso em 5 ago. 2006.

FREITAS, D. N. T. de. A avaliação da educação básica no Brasil: dimensão normativa, pedagógica e educativa. Campinas: Autores Associados, 2007. (Coleção Educação Contemporânea.)

GARET, M. et al. (Ed.). What makes Professional development effective? Results from a national sample of teachers. American Educational Research Journal. Thousand Oaks: Sage Publications, v, 38, n. 4, p. 915-945, Win. 2001.

GATTI, B. A. Avaliação de professores: um campo complexo. Estudos em Avaliação Educacional, São Paulo: Fundação Carlos Chagas, v. 22, n. 48, p. 77-88, jan./abr. 2011. 
GATTI, B. A. Análise das políticas públicas para formação continuada no Brasil na última década. Revista Brasileira de Educação, Rio de Janeiro: Anped/Autores Associados, v. 13, n. 37, p. 57-70, jan./abr. 2008.

GUSKEY, T.; SPARKS, D. Linking professional development to improvements in student learning. REUNIÃO ANUAL DA ASSOCIAÇÃO AMERICANA DE PESQUISA EDUCACIONAL, abr. 2002, Nova Orleans. Disponível em: <http://www.eric.ed.gov:80/ERICWebPortal/search/detailmini.jsp?_nfpb=true\&_\&E RICExtSearch_SearchValue_0=ED464112\&ERICExtSearch_SearchType_0=no\&accn o=ED464112 >. Acesso em: 19 jan. 2011.

GUSKEY, T.; SPARKS, D. Exploring the relationship between staff development and improvements in student learning. Journal of Staff Development, Oxford: National Staff Development Council, v. 17, n. 4, 1996. Disponível em: <http://www.learningforward.org/news/ jsd/f_gusky.cfm>. Acesso em: 23 fev. 2011. GUSKEY, T.; SPARKS, D. Complexities in evaluating the effects of staff development programs. REUNIÃO ANUAL DA ASSOCIAÇÃO AMERICANA DE PESQUISA EDUCACIONAL, abr. 1991, Chicago. Disponível em: <http://www.eric.ed.gov/ PDFS/ED331795.pdf>. Acesso em: 19 jan. 2011.

HAERTEL, E. The Valid Use of Student Performance Measures for Teacher Evaluation. Educational Evaluation and Policy Analysis, 8, 1986, p. 45-60. Disponível em: <http://www.jstor.org/stable/1163819>. Acesso em 6 nov. 2009.

NAVARRO, J. C. La evaluación y las actitudes de los docentes frente a ella: dificultades y alternativas de política. UNESCO. Evaluar las evaluaciones: una mirada política acerca de las evaluaciones de la calidad educativa. Buenos Aires: IIPE/UNESCO, 2003, p. 147164.

PIATTI, C. B. Formação continuada: reflexos na prática dos professores participantes do Programa de Formação de Professores Alfabetizadores - Profa. 2006. Dissertação (Mestrado em Educação) - Universidade Católica Dom Bosco, Campo Grande, MS, 2006.

PRADA, L. E. A. Formação Continuada de Professores: experiências em alguns países. Revista Online da Biblioteca. Prof. Joel Martins. Campinas, v. 2, n. 3, p. 97-116, jun. 2001. SÃO PAULO (a), Secretaria da Educação do Estado. Comunicado SE/95.

SÃO PAULO (b), Secretaria da Educação do Estado. Documento de Implantação do SARESP. 1996.

SÃO PAULO (c), Secretaria da Educação do Estado. Programa de Educação Continuada (1996-1998). Julho de 1996.

SÃO PAULO. Secretaria da Educação do Estado. SARESP 98, Manual de orientação. São Paulo: FDE, 1998, p. 01.

SÃO PAULO. Secretaria da Educação do Estado. SARESP - Sistema de Avaliação do Rendimento Escolar do Estado de São Paulo: Os avanços na construção de uma cultura avaliativa na Rede de Ensino Paulista. No 02, Agosto de 1999. São Paulo. Articulando a avaliação, gestão e formação no SARESP, FDE, 1998.

SÃO PAULO. Lei Complementar n 1078, de 17 de dezembro de 2008.

SCRIVEN, M. Validity in Personnel Evaluation. Journal of Personnel Evaluation in Education, 1,Hingham: mKlumer Academic Publishers, p. 9-23, 1987.

SOARES, J. F. Melhoria do desempenho cognitivo dos alunos do ensino fundamental. 
Cadernos de Pesquisa, São Paulo, v. 37, n. 130, p. 135-160, 2007. Disponível em: <http://www.scielo.br/scielo.php. ISSN 0100-1574>. Acesso em: 22 nov. 2008.

SOUZA, D. T. R. Formação continuada de professores e fracasso escolar: problematizando o argumento da incompetência. Educação e Pesquisa, São Paulo: FEUSP, v. 32, n. 3, p. 477-492, set./dez. 2006.

TORRES, R. M. Tendências da formação docente nos anos 90. WARDE, M. (org.). Novas políticas educacionais: críticas e perspectivas. São Paulo: PUC, 1998, p. 173-191.

WEINBERG, M. Premiar o mérito. Revista Veja, n. 2047. 13/2/2008. Disponível em: <http://veja.abril.com.br/130208/entrevista.shtml>. Acesso em: 20 nov. 2009.

WEY, V. L. A capacitação de educadores no contexto da política educacional da SEE/SP. BICUDO, M. A. V.; SILVA JÚNIOR, C. A. Formação do educador e avaliação educacional: formação inicial e contínua. São Paulo: Editora UNESP, 1999, p. 227-247.

WILSON, S. M.; BERNE, J. Teacher Learning and the Acquisition of Professional Knowledge: An Examination of Research on Contemporary Professional Development. Review of Research in Education, v. 24, p. 173-209, 1999. Disponível em: <http://www.jstor.org/stable/1167270>. Acesso em: 29 jan. 2010. 


\section{Notas}

1 Apesar de ter constituído aspecto central na pesquisa original, os depoimentos obtidos junto aos técnicos das diretorias de ensino, FDE e CENP não serão utilizados no presente artigo, por limitações de espaço. Assim, objetiva-se aqui uma análise crítica das declarações dos documentos oficiais e o questionamento da lógica utilizada para a justificativa da política, suprimindo-se a análise daqueles depoimentos.

2 O Saeb - Sistema de Avaliação da Educação Básica - é a avaliação proposta em nível nacional, de caráter amostral, proposta pelo MEC. Essa avaliação é realizada a cada dois anos, utilizando testes padronizados e questionários, e abrange amostras de todas as unidades da federação. A partir de 2005, o Saeb é composto pela Avaliação Nacional da Educação Básica (Aneb) - que mantém as características do Saeb, com caráter sistêmico geral e sendo aplicada a uma amostra aleatória de estudantes - e pela Avaliação Nacional do Rendimento Escolar (Anresc). De maior extensão, com foco em cada unidade escolar, pretende coletar informações sobre o desempenho em leitura e matemática dos alunos das escolas urbanas de $4^{\mathrm{a}}$ e $8^{\mathrm{a}}$ séries da rede pública brasileira.

3 De maneira geral, tais objetivos permanecem em todas as aferições do Saresp, com exceção do ano de 2001, quando a avaliação assumiu caráter bastante específico: “embasar as decisões quanto ao encaminhamento de cada aluno para a continuidade de estudos ou para a recuperação de ciclos" (SÃO PAULO, Saresp 2002. Disponível em: http://saresp.edunet.sp.gov.br/2002/subpages/desenh_metd.htm. Acesso em 24 mar. 2010).

4 Qualidade essa cuja definição e cujos parâmetros variam muito, tanto nas discussões acadêmicas quanto entre gestores e técnicos de educação.

5 FULLER, B.; CLARKE, P. Raising school effects while ignoring culture? Local conditions and the influence of classroom tools, rules, and pedagogy. Review of Educational Research, v. 64, n. 1, 1994.

6 A variable that is positively correlated with another can always be used to infer the presence of the other, but cannot in general be used to explain it or evaluate it. Incorrect use of a correlate (or a factor in a factor analysis) as if it were an explanation of, a substitute for, or a valid evaluative criterion of, another variable are examples of what is here called the fallacy of statistical subrogation (SCRIVEN, 1987, p. 11).

7 Evaluation procedures, like uses of psychological tests, are valid or invalid. They are valid to the extent that they correctly identify the merit of whatever or whomever is being evaluated. (The kind of validity involved in both cases is the same, namely construct validity4, to which all other types reduce) (SCRIVEN, 1987, p. 9).

8 (...) tests can measure only a subset of important learning objectives, and if teachers are rated on their students' attainment of just those outcomes, instruction of unmeasured objectives may be slighted (Elliott \& Hall, 1985). For all these reasons, it has become a common place that standardized student achievement tests are ill-suited for teacher evaluation (HAERTEL, 1986, p. 46). 
9 No caso do Brasil, para se ter uma ideia da dimensão da influência da formação docente na qualidade da educação, vale mencionar que, segundo Creso Franco, muitos estados brasileiros que têm sistemas próprios de avaliação de rendimento dos alunos atestam que um de seus objetivos principais é obter informações que subsidiem programas de formação ou capacitação docente. (FRANCO, 2005, p. 7)

Recebido: $13 / 04 / 2011$

Aprovado: 29/09/2011

Contato:

Fundação Carlos Chagas

Rua Quitanduba, 363

Butantã

CEP 05516-030

São Paulo, SP

Brasil 